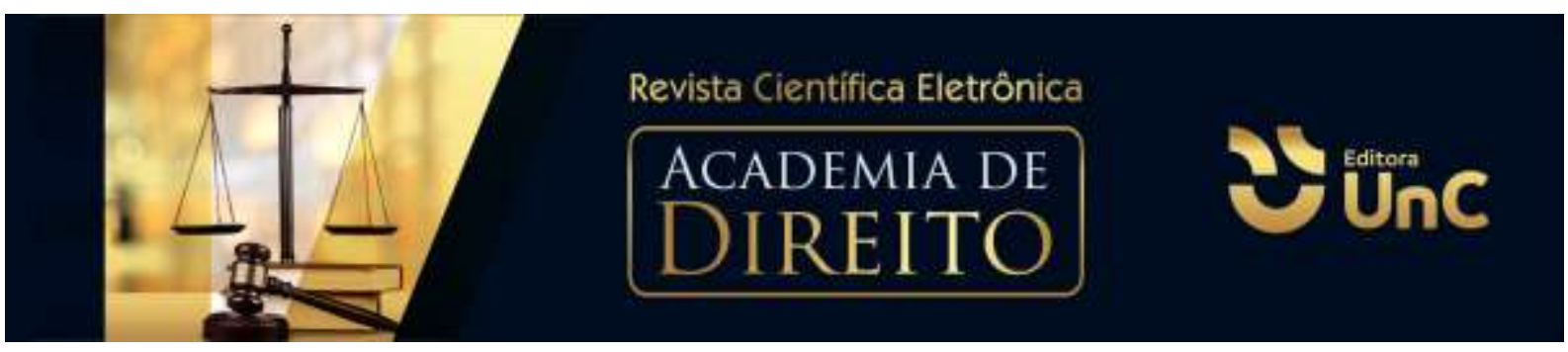

\title{
A DESBUROCRATIZAÇÃO DOS PROCEDIMENTOS LICITATÓRIOS EM BUSCA DE CELERIDADE NO COMBATE AO CORONAVIRUS
}

\section{THE DEBUROCRATIZATION OF BIDDING PROCEDURES IN SEARCH OF CELERITY IN THE FIGHT AGAINST CORONAVIRUS}

\author{
Diogo Oliveira ${ }^{1}$ \\ Cilmara Corrêa de Lima Fante ${ }^{2}$
}

\begin{abstract}
RESUMO
O presente artigo busca estudar sobre a desburocratização dos procedimentos licitatórios, que surgiram visando a celeridade nas contratações públicas para o enfrentamento da emergência sanitária causada pelo novo coronavírus. A administração pública deve agir pautada estritamente nos ditames legais, assim na ocorrência de situações como a que se vive no momento, necessário que sejam criados mecanismos legais a fim de possibilitar celeridade nos procedimentos da administração pública para atender a demanda de forma eficiente. Por meio de pesquisa bibliográfica, embasada no método dedutivo, constatou-se que as inovações legislativas instituídas pela Lei $n^{\circ} 13.979 / 2020$ e suas alterações dada pela Lei $n^{\circ}$ 14.035/2020, implementaram mecanismos simplificados nas contratações públicas para o enfrentamento da emergência de saúde, considerando a celeridade e simplicidade que aduzem, via de regra, especificamente nas contratações que se relacionam a contenção da disseminação do novo coronavírus.
\end{abstract}

Palavras chave: Administração pública. Licitação. Contratos. Coronavírus.

\begin{abstract}
This article seeks to study about the reduction of bureaucracy in bidding procedures, which arose with a view to speeding public procurement to face the health emergency caused by the new coronavirus. The public administration must act strictly based on legal dictates, as well as in the occurrence of situations such as the one currently experienced, it is necessary that legal mechanisms be created in order to allow speed in the procedures of public administration to meet the demand efficiently. Through bibliographic research, based on the deductive method, it was found that the legislative
\end{abstract}

\footnotetext{
${ }^{1}$ Graduando de Direito pela Universidade do Contestado. Campus Marcílio Dias. Canoinhas. Santa Catarina. Brasil. E-mail: Diogo.1102@hotmail.com

${ }^{2}$ Advogada, mestre em Desenvolivmento Regional pela Universidade do Contestado. Professora no curso de Direito da Universidade do Contestado. Santa Catarina. Brasil. E-mail: cilmarafante@unc.br. ORCID: https://orcid.org/0000-0003-2389-9912
} 
innovations instituted by Law 13.979/2020 and its amendments given by Law $14.035 / 2020$, implemented simplified mechanisms in public contracting to face the health emergency, considering the speed and simplicity that add, as a rule, specifically in the contracts that are related to containing the spread of the new coronavirus.

Keywords: Public Administration. Bidding. Contracts. Coronavirus.

\section{INTRODUÇÃo}

O ano de 2020 vem sendo marcado pela pandemia mundial do novo coronavírus e as medidas de enfretamento que cada país vem tomando para conter sua disseminação e consequências.

Com a chegada no Brasil em meados de fevereiro do ano presente, logo, trouxe vasto número de infectados e até mortes. Assim, em março, o Brasil decretou estado de emergência de saúde pública, expedindo medidas provisórias, decretos e outros atos normativos para conter a disseminação do Covid-19.

Para atender a demanda da saúde pública, as contratações da administração pública sofreram alterações nos seus ritos, visando celeridade nos procedimentos para aquisição ou contratação de bens, serviços e insumos destinados ao enfrentamento da emergência de saúde pública de importância internacional decorrente do coronavírus.

Neste diapasão, buscou-se a breve explanação sobre a administração pública e contratos públicos, fazendo um comparativo entre os procedimentos para contratações públicas elencados pela Lei $n^{\circ} 8.666 / 93$ e os aduzidos por suas alterações, que apresenta ritos simplificados para atuação eficiente e célere da administração pública.

Entretanto, ainda que haja necessidade de ritos e procedimentos mais céleres, a administração pública deve observar requisitos para sua atuação e respeitar diversos princípios, como da legalidade, eficiência e finalidade.

Diante disso, o presente artigo buscará responder a seguinte questão problema: os procedimentos aduzidos pela Lei $n^{\circ} 13.979 / 20$, e suas alterações dada pela Lei n ${ }^{\circ} 14.035 / 2020$, trazem a celeridade almejada nos processos de contratações públicas, para o enfrentamento da emergência de saúde pública? 
Para tanto, por meio de pesquisa bibliográfica e documental, utilizando-se do método dedutivo, buscará, primeiramente, discorrer sobre a administração pública e seus princípios basilares, em seguida apresentar os procedimentos de contratação pública, baseado na Lei $n^{\circ}$ 8.666/93. Na sequência, realizar-se-á uma análise do contexto atual decorrente da disseminação do novo coronavírus.

Por fim, será analisado se os efeitos da Lei $n^{\circ} 13.979 / 2020$ trouxeram maior celeridade nas contratações públicas para o enfrentamento da emergência de saúde pública atual.

\section{A ADMINISTRAÇÃO PÚBLICA E OS PRINCIPIOS DA LEGALIDADE, EFECIENCIA E FINALIDADE}

A expressão "Administração Pública" relaciona-se à gestão de interesses públicos e, por essa razão, compreende as pessoas públicas, que devem atuar na defesa e promoção desses interesses, e as atividades administrativas (OLIVEIRA, 2015).

A Administração Pública corresponde à face do Estado (o EstadoAdministração) que atua no desempenho da função administrativa, objetivando atender concretamente os interesses coletivos. No sentido subjetivo, formal ou orgânico, a Administração Pública compreende um conjunto de entidades jurídicas (de direito público ou de direito privado), de órgãos públicos e de agentes públicos, que formam o aparelhamento orgânico e compõem a estrutura formal da Administração (CUNHA JUNIOR, 2015).

Em razão do princípio da reserva legal, as entidades administrativas só podem desempenhar as atividades que estiverem, especialmente, previstas na respectiva lei de criação ou autorizativa. A atuação administrativa em desconformidade com os limites e com as possibilidades legais deve ser considerada inválida (OLIVEIRA, 2015).

Esses limites por vezes são caracterizados por princípios que regem as ações dos agentes administrativos, em especial o da legalidade, eficiência e finalidade dentre outros que estão previstos no artigo 37 da Constituição Federal (BRASIL,1988).

Os princípios administrativos são os postulados fundamentais que inspiram todo o modo de agir da Administração Pública, representam cânones pré-normativos, 
norteando a conduta do Estado quando no exercício de atividades administrativas (CARVALHO FILHO, 2016).

O princípio da legalidade baseia-se no Estado Democrático de Direito e garante que todos os conflitos sejam resolvidos pela lei, trazendo como consequência maior limitação à discricionariedade administrativa, em decorrência da submissão da Administração Pública a princípios e valores, e a ampliação do controle judicial (DI PETRO, 2018).

Por outro lado, preceitua Meirelles (2016) os limites impostos pelo princípio da legalidade na Administração Pública, na qual não há liberdade nem vontade pessoal, enquanto na administração particular é lícito fazer tudo que a lei não proíbe, na Administração Pública só é permitido fazer o que a lei autoriza.

Neste sentido, considerando que o principal objetivo da administração pública se baseia no atendimento do interesse público, o princípio da eficiência busca implementar um modelo de administração pública gerencial voltada para um controle de resultados da atuação estatal, trazendo maior qualidade, competência e eficiência possível em prol da sociedade.

Introduzido na Constituição Federal através da Emenda Constitucional n 19/98 o princípio da eficiência determina que a atividade da Administração Pública deve ter em mira a obrigação de ser eficiente. "Trata-se de um alerta, de uma advertência e de uma imposição do constituinte derivado, que busca um Estado avançado, cuja atuação prime pela correção e pela competência" (MENDES; BRANCO, 2014, p. 792).

Di Pietro (2018, p. 151), discorre que:

\begin{abstract}
O princípio da eficiência, apresenta-se sob dois aspectos, podendo tanto ser considerado em relação à forma de atuação do agente público, do qual se espera o melhor desempenho possível de suas atuações e atribuições, para lograr os melhores resultados, como também em relação ao modo racional de se organizar, estruturar, disciplinar a administração pública, e também com o intuito de alcance de resultados na prestação do serviço público.
\end{abstract}

Todavia, afirma-se ainda, que de nada adianta a referência expressa na Constituição se não houver por parte da Administração a efetiva intenção de melhorar a gestão da coisa pública e dos interesses da sociedade, ou seja "com efeito, nenhum órgão público se tornará eficiente por ter sido a eficiência qualificada como princípio na Constituição" (CARVALHO FILHO, 2016, p. 458). 
Nota-se que diante de tal princípio, o que se espera do Estado é qualidade e eficiência dos serviços públicos a fim de tornar a convivência entre a administração pública e administrados harmoniosa na satisfação do bem comum.

Na sequencia, evidencia-se o princípio da finalidade, segundo o qual discorre José dos Santos Carvalho Filho (2016, p. 76) "o alvo a ser alcançado pela Administração é somente o interesse público, e não se alcança o interesse público se for perseguido o interesse particular, porquanto haverá nesse caso sempre uma atuação discriminatória".

Para Di Pietro (2018, p. 117) "o princípio da finalidade consiste em lembrar que toda atividade de administração deve ser útil ao interesse que o administrador deve satisfazer".

Assim, pode-se entender que a administração pública deve agir sempre em conformidade com a lei (princípio da legalidade), atendendo com soluções efetivas de fatos calculando os quesitos celeridade, eficácia e economicidade (princípio da eficiência) e também alcançando as demandas específicas e necessárias do interesse público (princípio da finalidade).

\section{CONTRATOS PÚBLICOS E PROCESSO LICITATÓRIO}

As contratações feitas pela administração pública seguem, além de princípios basilares como os elencados no tópico anterior, diretrizes pontuadas pela legislação vigente, que tem como base a previsão constitucional do processo licitatório insculpida no Art. 37, XXI, que versa:

Art. 37. A administração pública direta e indireta de qualquer dos Poderes da União, dos Estados, do Distrito Federal e dos Municípios obedecerá aos princípios de legalidade, impessoalidade, moralidade, publicidade e eficiência e, também, ao seguinte:

XXI - ressalvados os casos especificados na legislação, as obras, serviços, compras e alienações serão contratados mediante processo de licitação pública que assegure igualdade de condições a todos os concorrentes, com cláusulas que estabeleçam obrigações de pagamento, mantidas as condições efetivas da proposta, nos termos da lei, o qual somente permitirá as exigências de qualificação técnica e econômica indispensáveis à garantia do cumprimento das obrigações (BRASIL,1988). 
A Lei n 8.666/1993, regulamenta o preceituado no Art. 37, XXI da Constituição Federal, institui normas que regulam as contratações de bens e ou serviço para a administração, assegurando que haja maior concorrência e competitividade respeitando os princípios que o norteia (BRASIL, 1993).

Com base, nos princípios basilares que norteiam a administração pública, a contratação por ela é realizada com base na Lei $n^{\circ}$ 8.666/93, na qual dispõe pormenorizadamente sobre o procedimento licitatório, ritos especiais de contratação e demais diretrizes.

Segundo Moreira Neto (2014), conceitua-se a licitação como processo administrativo vinculado destinado a selecionar o interessado que proponha contratar nas melhores condições para a Administração.

A atuação administrativa, ao contrário da atuação privada, exige maiores formalidades, tendo em vista a gestão da "coisa pública". Por essa razão, a Constituição e a Lei n 8.666/1993 exigem o cumprimento de algumas formalidades para celebração de contratos administrativos (OLIVEIRA, 2015).

Elucida Marinela (2018, p. 539), que:

\begin{abstract}
As formalidades que precedem o contrato, condições indispensáveis para sua realização, como a autorização para contratar, a exigência de licitação e os eventuais requisitos a serem atendidos, também se disciplinam pelo Direito Administrativo. Os contratos da Administração, sejam regidos ou não pelo direito público, também estão sujeitos a controle pelo Tribunal de Contas, com todas as suas consequências, exigindo-se, assim, a observância às regras dessa disciplina.
\end{abstract}

Para que a administração pública possa firmar um contrato administrativo, existem condições específicas atribuídas a ritos e ações desde seu início de processo como por exemplo o projeto básico, que é a definição prévia da obra a ser contratada (DI PIETRO, 2018).

Acentua-se formalidades expressas na Lei $n^{\circ} 8.666 / 1993$ que Oliveira (2015, p. 360) extrai sinteticamente:

a) realização de licitação, salvo as hipóteses legais de dispensa e inexigibilidade, devendo ser acostada a minuta do contrato ao instrumento convocatório;

b) forma escrita, salvo os ajustes para pequenas compras de pronto pagamento (art. 60, parágrafo único), bem como as hipóteses de boa-fé do 
contratado com o intuito de vedar o enriquecimento sem causa da Administração;

c) cláusulas necessárias (art. 55);

d) possibilidade de exigência de garantia (caução em dinheiro ou em títulos da dívida pública, seguro-garantia ou fiança bancária) nas contratações de obras, serviços e compras, desde que tal exigência conste do instrumento convocatório, não podendo a garantia ser superior a $5 \%$ do valor do contrato, salvo na hipótese de contratações de grande vulto, com alta complexidade técnica e riscos financeiros consideráveis, quando a garantia pode ser de até $10 \%$ do valor do contrato;

e) arquivamento dos contratos administrativos em ordem cronológica e o registro de seus extratos (art. 60);

f) os contratos devem mencionar "os nomes das partes e os de seus representantes, a finalidade, o ato que autorizou a sua lavratura, o número do processo da licitação, da dispensa ou de inexigibilidade, a sujeição dos contratantes às normas desta Lei e às cláusulas contratuais" (art. 61);

g) publicação na imprensa oficial dos contratos e seus aditamentos, ainda que de forma reduzida, que funciona como condição de sua eficácia (art. 61, parágrafo único).

Outra exigência formal para o contrato administrativo é a realização do procedimento licitatório, que só não ocorrerá nas hipóteses de dispensa ou inexigibilidade. Todavia, mesmo nesses casos, necessário o devido procedimento justificando a hipótese, conforme exigência do art. 26, da Lei $n^{\circ}$ 8.666/93 demonstrando as necessidades do Poder Público e as respectivas disponibilidades orçamentárias (MARINELA, 2018).

O sistema adotado pela lei para a formalização dos contratos administrativos se constitui de dois grupos. "Quando o contrato for precedido por concorrência ou por tomada de preços, ou envolver valores correspondentes a essas modalidades no caso de dispensa ou inexigibilidade de licitação, deve rotular-se como termo de contrato" (CARVALHO FILHO, 2016. p. 261).

Por dessas hipóteses, quando então o valor contratual será mais baixo, pode o termo de contrato ser substituído por instrumentos considerados de menor formalismo, como a carta-contrato, a nota de empenho de despesa, a autorização de compra ou a ordem de execução do serviço (CARVALHO FILHO, 2016).

As cláusulas necessárias do contrato administrativo estão elencadas no art. 55, da Lei $n^{\circ}$ 8.666/93 são obrigatórias e indispensáveis em todo contrato, devendo ser previstas de forma clara e precisa e sua ausência gera a nulidade do mesmo. (MARINELA, 2018).

Quanto à exigência da forma escrita do contrato, preceitua o art. 60, parágrafo único, da Lei n 8.666/1993, considerando "nulo e de nenhum efeito" o contrato verbal. 
A única exceção expressamente reconhecida refere-se aos contratos verbais de pequenas compras (até $\mathrm{R} \$ 8.800,00$ ) e pronto pagamento (MAZZA, 2020).

Para celebração destes contratos, tem-se todo o procedimento licitatório a ser percorrido, iniciado com sua fase interna onde deve-se fazer a exposição de motivos da contratação, justificando a necessidade do órgão na celebração do contrato e sua importância às atividades do ente estatal e à persecução do interesse público. A fase interna se encerra com a publicação do edital de convocação, marco inicial da fase externa (CARVALHO, 2015).

$\mathrm{Na}$ fase externa da licitação, tem-se o procedimento de habilitação e qualificação dos concorrentes, conforme o previsto no Art. 27 da Lei no 8.666/1993, para então adentrar na fase objetiva, onde são analisadas as propostas (MARINELA, 2018).

Na sequência, aprecia-se e julga-se as propostas dos licitantes habilitados, na parte denominada classificação e então chega-se ao rito final, denominado adjudicação, fase pela qual se declara o caráter satisfatório da proposta vencedora homologando-a (CARVALHO, 2015).

\section{CONTEXTUALIZAÇAO DA PANDEMIA DO CORONAVÍRUS}

Apesar de ter chegado ao conhecimento da população recentemente os primeiros indícios do coronavírus foram identificados no ano de 1960, caracterizado como uma família de vírus que culminam em doenças respiratórias semelhantes a um resfriado leve ou moderado, transmissível a seres humanos e animais. O novo agente do coronavírus denominado SARS-CoV-2-19, descoberto em 31 de dezembro de 2019 na cidade de Wuhan na China, iniciou uma cadeia de contágios registrando cerca de oitocentas pessoas diagnosticadas, com mortalidade de duzentas e cinquenta e nove destas (BRASIL, 2020).

Inicialmente, em 30 de janeiro de 2020, a Organização Mundial da Saúde (OMS) declarou que o surto do coronavírus (SARS-CoV-2-19) constituía Emergência de Saúde Pública de Importância Internacional (ESPII), que segundo a previsão do Regulamento Sanitário Internacional é o mais alto nível de alerta da Organização, posteriormente, após o vírus ter se espalhado por mais de 114 (cento e quatorze) 
países, a OMS em 11 de março de 2020, cerca de duas semanas após sua aparição em solo brasileiro, elevou o estado de calamidade para pandemia (OPAS, 2020).

No Brasil, o Ministério da Saúde registrou o primeiro caso no dia 26 de fevereiro de 2020, sendo consequentemente o primeiro país a registrar casos na América Latina, poucos dias depois, foi confirmada a primeira morte decorrente do coronavírus no Brasil (BRASIL, 2020).

Nesse contexto, foi promulgada a Lei Federal $n^{\circ} 13.979 / 20$, que dispõe sobre "as medidas para enfrentamento da emergência de saúde pública de importância internacional decorrente do coronavírus", posteriormente foi alterada pela Medida Provisória $\mathrm{n}^{\circ} 926$ de 20 de março do presente ano, convertendo-se na Lei $\mathrm{n}^{\circ}$ 14.035/20, trazendo regras específicas para as contratações de bens, serviço e insumos destinadas ao enfrentamento da emergência de saúde (BRASIL, 2020).

Dentre outras providencias, a lei estabelece normas mais flexíveis para a contratação de bens, serviços e insumos destinados ao enfrentamento da pandemia atual, aplicáveis às entidades da Administração Pública Direta e Indireta de todas as esferas federativas (BRASIL, 2020).

A falta de investimentos do Governo Federal na saúde pública e o aumento elevado de pessoas infectadas gerou uma grande preocupação das autoridades de Saúde que adotaram medidas preventivas para conter a disseminação do vírus, como distanciamento social e restrição de circulação de pessoas a fim de evitar aglomerações, fechamentos de escolas e universidades, paralisação de serviços não essenciais, dentre outros (MOTA, 2020).

Devido ao insuficiente conhecimento científico sobre o novo coronavírus e a capacidade de disseminação, surge à necessidade de alterações jurídicas para que o direito possa acompanhar a demanda social e auxiliar de modo efetivo na contenção da disseminação deste vírus (MOURA, 2020).

Nas contratações públicas, a urgência imposta pela pandemia trouxe legislação própria específica, na qual constam regras mais céleres para que a administração pública possa agir, sem fugir aos princípios que norteiam as licitações e contratações, da formalidade necessária (MOTA, 2020).

Cabe ressaltar a importância do direito fundamental à vida, insculpido na nossa Carta Magna, em seu art. $5^{\circ}$, caput. Esse direito, instituído como cláusula pétrea, é inviolável, possui amparo constitucional, e está sofrendo de forma direta com a 
disseminação do novo coronavírus e para seu combate foi necessário adquirir novos equipamentos como ventiladores pulmonares, monitores de sinais vitais, bombas de infusão, equipamentos de oximetria para suprir a demanda imposta pela pandemia, construir hospitais de campanha, entre outras medidas (MOURA, 2020).

Sendo assim, evidencia-se que a pandemia do coronavírus demandou alterações e inovações no âmbito jurídico, com a finalidade de facilitar as medidas de enfrentamento, aplicada nas contratações da Administração pública.

\section{EFEITOS DA LEI 13.979 DE 2020 NOS CONTRATOS LICITATÓRIOS}

A Constituição Federal em seu art. 37, inciso XXI, aduz possibilidade da contratação direta nos casos especificados pela lei (BRASIL, 1988).

Nesses casos, são presumidos os seguintes requisitos para dispensa da licitação (previstos no artigo 24, caput, IV, da Lei $n^{\circ}$ 8.666/93): (i) ocorrência de situação de emergência; (ii) necessidade de pronto atendimento da situação de emergência; (iii) existência de risco a segurança de pessoas, obras, prestação de serviços, equipamentos e outros bens, públicos ou particulares; e (iv) limitação da contratação à parcela necessária ao atendimento da situação de emergência (BRASIL,1993).

Dado o contexto atual com o intuito de proteger a coletividade, a Lei $n^{\circ}$ 13.979/2020 e suas alterações trouxeram regras flexíveis e simplificadas no âmbito das contratações públicas (BRASIL, 2020).

Entre as inúmeras alterações trazidas pela Lei $n^{\circ} 13.979 / 2020$, alterada pela Lei $n^{\circ} 14.035 / 20$ destacam-se as elencadas no quadro comparativo a seguir:

Quadro 1 - Alteração relativa à pandemia do COVID- 19.

\begin{tabular}{|c|c|c|}
\hline Alteração quanto & Lei $n^{\circ} 8.666 / 1993$ & Lei $n^{0} 13.979 / 2020$ \\
\hline $\begin{array}{lrr}\text { A } & \text { obrigatoriedade } & \text { do } \\
\text { Processo de Licitação. } & \end{array}$ & $\begin{array}{l}\text { Obrigatoriedade do processo } \\
\text { de licitação para aquisição de } \\
\text { bem ou serviço, inclusive para } \\
\text { insumos cotidianos da saúde } \\
\text { pública. }\end{array}$ & $\begin{array}{l}\text { Dispensável a licitação para } \\
\text { aquisição de bens, serviços, } \\
\text { inclusive de engenharia, e } \\
\text { insumos destinados ao } \\
\text { enfrentamento da emergência de } \\
\text { saúde pública. (Lei } \mathrm{n}^{\circ} \\
\text { 14.035/2020). }\end{array}$ \\
\hline Ao Estudo Prévio & $\begin{array}{l}\text { Obrigatória à elaboração de } \\
\text { estudos preliminares no } \\
\text { momento de planejamento da } \\
\text { contratação. }\end{array}$ & $\begin{array}{l}\text { Não é exigida a elaboração de } \\
\text { estudos preliminares quando se } \\
\text { tratar de bens e serviços comuns. }\end{array}$ \\
\hline
\end{tabular}




\begin{tabular}{|c|c|c|}
\hline $\begin{array}{l}\text { A possibilidade de } \\
\text { contratação de empresas } \\
\text { declaradas inidôneas ou } \\
\text { com suspensão do direito de } \\
\text { licitar/contratar com a } \\
\text { Administração Pública }\end{array}$ & $\begin{array}{l}\text { Proibição completa da ação de } \\
\text { licitar ou contratar com o Poder } \\
\text { Público. }\end{array}$ & $\begin{array}{l}\text { É possível a ação de licitar e } \\
\text { contratar caso } \quad \text { seja } \\
\text { comprovadamente o r único } \\
\text { fornecedor do bem ou serviço (Lei } \\
\left.n^{\circ} 14.035 / 2020\right) \text {. }\end{array}$ \\
\hline $\begin{array}{lr}\text { A possibilidade de } \\
\text { contratação de empresas } \\
\text { com dispensa de } \\
\text { apresentação } \\
\text { documentação relativa à } \\
\text { regularidade fiscal e } \\
\text { trabalhista ou um ou mais } \\
\text { requisitos de habilitação. }\end{array}$ & $\begin{array}{l}\text { É indispensável à } \\
\text { apresentação de documentos } \\
\text { relativos à regularidade fiscal e } \\
\text { trabalhista para a habilitação } \\
\text { da empresa. }\end{array}$ & $\begin{array}{l}\text { Havendo restrição de } \\
\text { fornecedores ou de prestadores } \\
\text { de serviço, mediante justificativa, } \\
\text { poderá dispensar a apresentação } \\
\text { de documentação relativa à } \\
\text { regularidade fiscal e trabalhista } \\
\text { ou, ainda, o cumprimento de um } \\
\text { ou mais requisitos de habilitação } \\
\left.\text { (Lei } n^{\circ} 14.035 / 2020\right) \text {. }\end{array}$ \\
\hline $\begin{array}{l}\text { A redução de prazos nos } \\
\text { procedimentos de pregão }\end{array}$ & $\begin{array}{l}\text { Prazos fixados para } \\
\text { apresentação de proposta e de } \\
8 \text { (oito) dias úteis e para } \\
\text { apresentação de razões } \\
\text { recursais e de contrarrazões } \\
\text { de } 3 \text { (três) dias úteis. }\end{array}$ & $\begin{array}{l}\text { Nos casos de licitação na } \\
\text { modalidade pregão, eletrônico ou } \\
\text { presencial, os prazos dos } \\
\text { procedimentos licitatórios serão } \\
\text { reduzidos pela metade (Lei } n^{\circ} \\
14.035 / 2020) \text {. }\end{array}$ \\
\hline $\begin{array}{l}\text { A dispensa de Audiência } \\
\text { Pública }\end{array}$ & $\begin{array}{l}\text { Os procedimentos licitatórios } \\
\text { cuja estimativa de valor supere } \\
\mathrm{R} \$ 1.500 .000,00 \text { (um milhão e } \\
\text { quinhentos mil reais), deverão } \\
\text { ser iniciados com a realização } \\
\text { de audiência pública prévia à } \\
\text { publicação do edital, } \\
\text { respeitados os prazos } \\
\text { previstos na Lei de Licitações. }\end{array}$ & $\begin{array}{l}\text { É dispensada a realização de } \\
\text { audiência pública nas Licitações } \\
\text { emergenciais } \\
\text { 14.035/2020). }\end{array}$ \\
\hline
\end{tabular}

Fonte: Dados da pesquisa (2020).

Diante da comparação apresentada, mostra-se que a Lei $n^{\circ} 13.979 / 2020$ por meio de seus dispositivos, possibilita que a Administração Pública haja de forma célere nas contratações atendendo principalmente o interesse público.

Considerando que a Administração Pública precisa adquirir respiradores, ventiladores pulmonares, máscaras e demais insumos voltados ao atendimento de pacientes em situações graves, decorrentes do COVID-19, e para que tal contratação ocorra em tempo hábil dada emergência, poderá ser realizada a contratação de empresa apta a fornecer, por meio do processo de dispensa de licitação, atendendo inclusive, ao princípio da eficiência (BOAVENTURA, 2020).

Anteriormente ao estado calamitoso, no ano de 2013, o Superior Tribunal de Justiça destacou que nas contratações da Administração Pública é necessário o critério legal de prévia licitação, salvo os casos de dispensa e inexigibilidade que exijam justificativa fundamentada do gestor público (STJ, 2013). 
Todavia, no contexto atual deve-se observar o parecer prolatado da Advocacia Geral da União:

\begin{abstract}
A Lei $n^{\circ} 8.666 / 1993$, enquanto norma geral de licitações e contratos, aplicase às contratações regidas pela Lei $\mathrm{n}^{\circ} 13.979 / 2020$ de forma subsidiária, naquilo que: a) não for tratado expressamente por esta Lei; e b) não estiver em desconformidade com o regime jurídico desta Lei (leia-se, não for tratado implicitamente pela Lei) (BRASIL, 2020. p. 3).
\end{abstract}

Baseada na explanação anterior do Superior Tribunal de Justiça, entende-se que a realização de licitação é regra, com necessidade de justificativa nas exceções que permitem sua dispensa e ou inexigibilidade. Alterado pela conjuntura atual, a excepcionalidade das permissões advindas da Lei $n^{\circ} 13.979 / 2020$, aplicando subsidiariamente a Lei $n^{\circ} 8.666 / 93$ por se tratar de norma geral naquilo que a nova lei não verse expressamente.

Justen Filho, et al. (2020, n.p.) adverte que no contexto atual, "deve prevalecer o entendimento de que a atuação dos agentes será norteada especificamente pela dimensão da proporcionalidade". Para o jurista, essa dimensão legitima a adoção de medidas concretas que se configurem, em vista das circunstâncias da realidade, como adequadas para enfrentar as exigências para evitar danos irreparáveis à saúde individual e coletiva.

Para Boaventura (2020) houve uma flexibilização da norma, no intuito de trazer maior celeridade aos procedimentos licitatórios, desmistificando a rigidez insculpida pela Lei $\mathrm{n}^{\circ} 8.666 / 93$, em prol aos direitos constitucionais do bem maior da vida e a saúde.

Todavia a falta de formalidade legais nas contratações públicas pode eivar o procedimento de vícios oriundos de valores subjetivos do agente administrativo, ou até mesmo na contratação de empresa não apta a prestar o serviço com a qualidade necessária para atender a demanda. Assim, mesmo que a contratação seja célere, o objetivo pode ser inalcançado de forma eficiente.

Com a alteração dada pela Lei $n^{\circ} 14.035 / 2020$, o texto inicial do art. $4^{\circ}$ da Lei n ${ }^{\circ} 13.979 / 2020$ foi modificado, dispensando a licitação para aquisição de bens, serviços, inclusive de engenharia, e insumos, não mais apenas aqueles necessariamente de saúde, contanto que destinados ao enfrentamento da pandemia atual (AGUIAR; NOBRE, 2020). 
Relativo a essa nova hipótese de dispensa é que a lei mencionada em seu artigo 4-B, incluído pela Lei $\mathrm{n}^{\circ} 14.035 / 2020$, prevê a presunção de atendimento das condições de ocorrência de situação de emergência, como, por exemplo, a necessidade de pronto atendimento da situação de emergência e a existência de risco a segurança de pessoas e bens. Dessa forma, nos casos de compras de bens e insumos de saúde para o enfrentamento da crise, há dispensa da comprovação dos requisitos acima mencionados, já que a legislação determinou que eles já foram atendidos (MOTA, 2020).

Outra simplificação diz respeito à etapa de gerenciamento de riscos da contratação, que será exigido somente durante a gestão do contrato não havendo a obrigatoriedade, portanto, de sua composição ocorrer na fase de planejamento (art. $4^{\circ}$-D), também incluído pela Lei $n^{\circ} 14.035 / 2020$ (BRASIL, 2020).

Nas aquisições ou contratações de bens, serviços e insumos previstas pela norma, que deverão observar as exigências elencadas pelo $\S 1^{\circ}$ do art. $4^{\circ}-E$, incluído pela Lei $n^{\circ} 14.035 / 2020$, excepcionalmente e mediante justificativa da autoridade competente $\left(\S 2^{\circ}\right)$ poderá ser dispensada a estimativa de preços mencionada no inc. $\mathrm{VI}$, do $\$ 1^{\circ}$, do mesmo artigo (CORREA, 2020).

Visando proteger a vida, como bem jurídico principal, outro aspecto relevante da Lei $n^{\circ} 13.979 / 2020$ é a previsão constante no parágrafo $3^{\circ}$ do art. $4^{\circ}$, hipótese em que o gestor poderá contratar com empresa declarada inidônea ou com seu direito suspenso de licitar e contratar com a Administração pública, quando for à única fornecedora do bem ou serviço a ser adquirido (BOAVENTURA, 2020).

Em regra geral, com fulcro na Lei $n^{\circ} 8.666 / 93$, existe proibição completa da ação de licitar ou contratar com o Poder Público por estas empresas, entretanto, dado a situação, possível a contratação de fornecedor que estejam com inidoneidade declarada ou com o direito de participar de licitação, caso seja comprovadamente o único fornecedor (LUCAS; PEIXE; SANTOS, 2020).

A nova lei trouxe também em seu art. $4^{\circ} \mathrm{F}$ a possibilidade de dispensa de documentos de habilitação quando houver restrição de fornecedores ou prestadores de serviço, com o intuito ampliar a participação de empresas em um processo licitatório trazendo maior agilidade e celeridade aos procedimentos de aquisição, essa flexibilização da norma desmistifica a rigidez insculpida pela Lei $n^{\circ}$ 8.666/93 demonstrando a desnecessidade de formalismo. 
Importante destacar a disposição do art. $4^{\circ} \mathrm{G}$, incluída na Lei n ${ }^{\circ} 13.979 / 2020$, por meio da alteração dada pela Lei no $14.035 / 2020$, em que há a previsão de prazos reduzidos pela metade para a modalidade de Pregão, seja eletrônico ou presencial (BOAVENTURA, 2020).

Com base nos princípios constitucionais anteriormente destacados, destaca-se que a dispensa de licitação estabelecida pela Lei no 13.979/2020 pode ser utilizada em tempos de crise, contudo, mediante processo administrativo, devidamente justificado e motivado pelos agentes públicos.

Assim, vê-se que a norma esculpida pela lei de combate ao coronavírus não constitui um salvo conduto para aquisições sem licitação, continuando vigentes as recomendações do art. 24 da Lei $n^{\circ} 8.666 / 93$.

\section{CONSIDERAÇÕES FINAIS}

Ante o cenário pandêmico, a administração pública buscou soluções para atender a alta demanda oriunda do estado de emergência da saúde pública. Com base na pesquisa acima exposta, vê-se que as novas normas para as contratações públicas, com base na Lei $n^{\circ} 13.979 / 20$ e suas alterações dadas pela Lei $n^{\circ} 14.035 / 20$, apresentam ritos mais céleres quando comparados ao da Lei $n^{\circ} 8.666 / 93$.

No que concerne a observância dos princípios basilares da administração pública, tem-se que a nova lei respeita a legalidade, e com a celeridade que seus ritos apresentam, buscam alcançar sua finalidade, que ante a situação atual, não seria alcançada com ritos morosos, em vista do estado de emergência de saúde pública.

Mister que para dispensa da licitação ou rito simplificado, a contratação pública deve pautar-se em justificativa fundamentada, ao contrário o agente administrativo poderá ser responsabilizado pelo seu excesso.

Frisa-se que a alteração implementada não suprime a anterior, apenas deve ser utilizada nos casos que versa especificamente as situações de combate frente a crise sanitária.

Seguindo tais parâmetros os procedimentos simplificados das contratações públicas, regulamentados pela Lei $n^{\circ} 13.979 / 20$ e suas alterações, conferem celeridade essencial para atender a demanda do estado de emergência de saúde 
pública atual, respeitando os princípios em pauta e possuindo formalidades especificas para evitar sua utilização desorientada.

Empresta-se o raciocínio penalista de forma análoga, que "é melhor a absolvição de cem culpados, do que a condenação de um inocente". Voltada à lógica da presente pesquisa, preferível um rito legal menos burocrático, mas que seja célere e eficiente, do que a manutenção de um procedimento formalista, sob pena de acarretar perda de vidas diante de um cenário imprevisível, como é o da situação atual não abarcando sua finalidade precípua de proteção a saúde e a vida da população brasileira.

A pandemia produz mazelas para toda a sociedade, contudo a superação dos problemas requer esforço comum das autoridades administrativas e a sociedade civil.

Vislumbra-se após esta crise a emergência de reavaliação do modelo legal licitatória instituído pela Lei $n^{\circ} 8.666 / 93$ e a possibilidade de um modelo atual, célere, pautada na estrita legalidade, trazendo eficiência para a aplicação gestão dos recursos na contratação pública, sem, no entanto, deixar de penalizar o agente público que agir excessivamente e contrário aos ditames legais.

\section{REFERENCIAS}

AGUIAR, Simone Coelho; NOBRE, Emily Solon Marquinho. Lei n ${ }^{0} 13.979 / 2020$ e o regime emergencial da dispensa de licitação do coronavírus. Revista Controle, Fortaleza, v. 18, n.2, p. 77-108, jul./dez. 2020. Disponível em:<file:///C:/Users/itaja/Downloads/NOBRE_AGUIAR,2020\%20(COVID\%20E\%20L EI\%201397920).pdf>. Acesso em 12 set. 2020.

BOAVENTURA, Carmen leda. Requisitos de habilitação nos procedimentos licitatórios: uma análise sob a ótica jurídicoconstitucional. Disponível em: www.licitacaoecontrato.com.br. Acesso em 16 set. 2020.

BOAVENTURA. Carmen leda. Breves Considerações sobre a Lei 13.979/2020 e a Pandemia do Coronavírus. Disponível em:<https://ronnycharles.com.br/wpcontent/uploads/2020/04/Artigo-Carmen.-VersA\%CC\%83\%C2\%A3o-final.pdf>. Acesso em 16 set. 2020.

BRASIL. Constituição da República Federativa do Brasil. 29. Ed. Brasília: Congresso Nacional, 1988.

BRASIL. Lei $\mathbf{n}^{\circ} \mathbf{8 . 6 6 6}$, de 21 de junho de 1993. Disponível em:<http://www.planalto.gov.br/ccivil_03/LEIS/L8666cons.htm>. Acesso em 30 mar. 2020. 
BRASIL. Lei $n^{\circ} 13.979$ de 6 de fevereiro de 2020. Disponível em:<http://www.planalto.gov.br/ccivil_03/_ato2019-2022/2020/lei/l13979.htm.>. Acesso em 19 set. 2020.

BRASIL. Lei $n^{\circ} 14.035$ de 11 de agosto de 2020. Disponível em:<http://www.planalto.gov.br/ccivil_03/_ato2019-2022/2020/lei/L14035.htm>. Acesso em 18 set. 2020.

BRASIL. Medida Provisória $\mathbf{n}^{\circ} 926$ de 2020. Disponível em:<https://www.congressonacional.leg.br/materias/medidas-provisorias//mpv/141144>. Acesso em 19 set. 2020.

BRASIL. Ministério da Saúde. O que é coronavírus? (Covid-19). Governo do Brasil, Brasília, DF, 2020b. Disponível em: <https://bit.ly/2A9wfck>. Acesso em: 19 set. 2020.

BRASIL. Parecer 00006 de 2020. Premissas adicionais para utilização de minutas de contratação fundadas na Lei $n^{\circ} 13.979 / 20$ e encaminhamento de minutas de serviços de engenharia para análise superior. Advocacia-Geral da União. Disponível em: <https://www.gov.br/agu/pt-br/composicao/consultoria-geralda-uniao-1/modelos-de-convenios-licitacoes-e-contratos/modelos-de-licitacoes-econtratos/covid-19-lei-no-14-035-20 >. Acesso em: 23 ago. 2020.

BRASIL. Superior Tribunal de Justiça. REsp 1.205.605/SP, Rel. Min. Eliana Calmon, DJ de 15.08.2013. Disponível em: http://stj.jusbrasil.com.br/jurisprudencia/ 24047603/recurso-especial-resp-120505-sp-2020-0142113-s-stj/inteiro-teor24047604?ref=serp. Acesso em: 24 ago.2020.

CARVALHO, Matheus. Manual de direito administrativo. 2. ed. Salvador: Editora JusPodivm, 2015.

CARVALHO FILHO, José dos Santos. Manual de direito administrativo. 30 ed. Rev. Ampl. Atual. São Paulo: Atlas, 2016.

CORREA, Rogério. Nova Lei 14.035/20: conheça os principais destaques para as licitações e contratações públicas. Revista Inove. Disponível em:<https://www.inovecapacitacao.com.br/nova-lei-14-035-20-conheca-os-principaisdestaques-para-as-licitacoes-e-contratacoes-publicas/>. Acesso em 18 set. 2020.

CUNHA JUNIOR, Dirley da. Curso de direito administrativo. 14. ed. Salvador: Juspodivm, 2015.

DI PIETRO, Maria Sylvia Zanella. Direito administrativo. 31. ed. Rio de Janeiro: Forense, 2018.

JUSTEN FILHO, Marçal...[et al.]. Covid-19 e o direito brasileiro. In: JUSTEN FILHO, Marçal...[et al.]. Um novo modelo de licitações e contratações administrativas. 1 ed. Curitiba: Justen, Pereira, Oliveira \& Talamini, 2020. 
LUCAS, João Victor; SANTOS, Joselita Anunciação; PEIXE, Blênio Cezar Severo. Fatores Determinantes das Teorias do Caos e da Complexidade e o Efeito da Pandemia da Covid-19 no Processo Licitatório Brasileiro: um Estudo sobre a Administração Pública. In: CONGRESSO USP DE INICIAÇÃO CIENTÍFICA EM CONTABILIDADE; 17. 2020. São Paulo. Anais 2020. São Paulo: USP, 2020. Disponível em: https://congressousp.fipecafi.org/anais/Anais2020/ ArtigosDownload/2880.pdf. Acesso em 14 set.2020.

MARINELA, Fernanda. Direito administrativo. 12. ed. São Paulo: Saraiva, 2018. MAZZA, Alexandre. Manual de direito administrativo. 10. ed. São Paulo: Saraiva, 2020.

MEIRELLES, Hely Lopes. Direito administrativo brasileiro. 42. ed. São Paulo: Malheiros, 2016.

MENDES, Gilmar Ferreira; BRANCO, Paulo Gustavo Gonet. Curso de direito constitucional. 9 ed. São Paulo: Saraiva, 2014.

MOREIRA NETO, Diogo de Figueiredo. Curso de direito administrativo: parte introdutória, parte geral e parte especial. 16. ed. Rio de Janeiro: Forense, 2014.

MOURA, Larissa. Covid-19 e o embate entre o direito de ir e vir e o direito à saúde. Revista Jus.com.br, mar. 2020. Disponível em: <https://jus.com.br/artigos/80571/ covid-19-e-o-embate-entre-o-direito-de-ir-e-vir-e-o-direito-a-saude>. Acesso em 14 set. 2020.

MOTA, Leonardo. Impactos da covid-19 nas contratações públicas - comentários à lei $n^{\circ}$ 13.979/2020, atualizada pelas medidas provisórias n 926, 928 e 951.

Excelência em Educação. 09 jun. 2020. Disponível em:

$<$ https://excelenciaeducacao.com.br/2020/06/impactos-covid-contratacoespublicas/>. Acesso em 19 set. 2020.

OLIVEIRA, Rafael Carvalho Rezende. Administração pública, concessões e terceiro setor. 3. ed. rev., ampl. e atual. Rio de Janeiro: Forense; São Paulo: MÉTODO, 2015.

OPAS. Organização Pan-Americana da Saúde. OMS afirma que COVID-19 é agora caracterizada como pandemia.2020. Disponível em: <https://www.paho.org/bra/ index.php?option=com_content\&view=article\&id=6120:oms-afirma-que-covid-19-eagora-caracterizada-como-pandemia\&Itemid=812>. Acessa em 18 set. 2020.

Artigo recebido em: 07/10/2020

Artigo aceito em: 24/11/2020

Artigo publicado em: 04/03/2021 